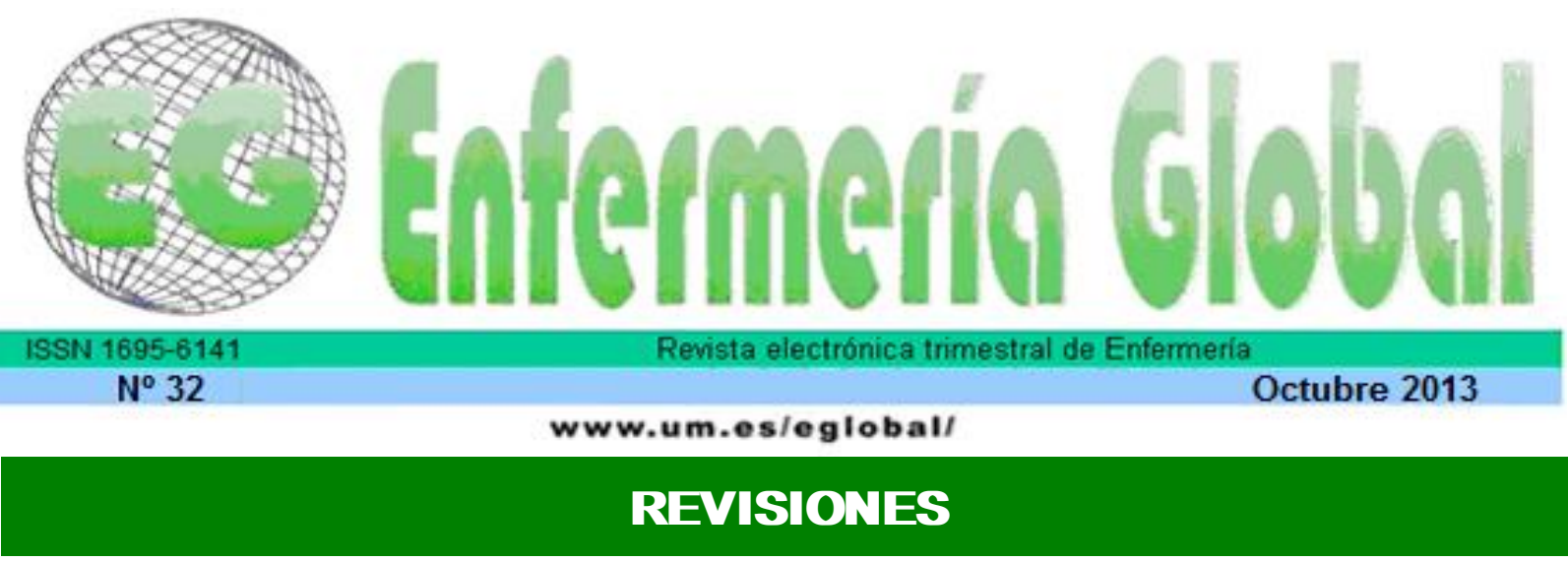

\title{
Textos de enfermería impresos en España durante los siglos XVI y XVII disponibles en bibliotecas digitales
}

Nursing texts printed in Spain during the sixteenth and seventeenth centuries available in digital libraries

\section{*León Molina, Joaquín}

*Doctorando en el Programa Ciencias Clínicas en Medicina. Lcdo. en Documentación. Enfermero Área Calidad del Hospital Clínico Universitario Virgen de la Arrixaca de Murcia. E-mail: joaquin.leon@um.es

Palabras clave: Historia de enfermería; manuales de enfermería en los siglos XVI y XVII; bibliotecas digitales

Keywords: History of nursing; nursing manuals in the sixteenth and seventeenth centuries; digital libraries.

\section{RESUMEN}

Se identifican en bibliografía los textos de enfermería impresos en España durante los siglos XVI y $\mathrm{XVII}$, que se supone son las bases de la enfermería española actual. El objetivo del trabajo tiene la doble vertiente del estudio de los manuales de enfermería y de las posibilidades de su recuperación y consulta en bibliotecas digitales. Para la obtención del objetivo se ha consultado bibliografía pertinente donde se han identificado los textos y extraído comentarios. Se han seleccionado bibliotecas digitales y se ha procedido a la búsqueda y recuperación. De los cuatro textos más significativos se han recuperado tres de ellos.

\section{ABSTRACT}

The texts of nursing printed in Spain during the $16^{\text {th }}$ and $17^{\text {th }}$ century that are supposed to be the bases of Current Spanish nursing are identified. The aim of this work has the twofold aspect of the study of nursing textbooks and the possibilities of recovering and querying digital libraries. To obtain the goal, relevant literature where texts have been identified and some comments were removed has been consulted. Digital libraries have been selected and preceded to search and retrieval. Of the four most significant texts have recovered three. 


\section{INTRODUCCIÓN}

La historia de la Enfermería española obliga a remitirnos a los siglos XVI y XVII. La asistencia sanitaria prestada en los hospitales en estos siglos experimenta un importante avance por la preocupación de los monarcas en mejorarla, tanto con la construcción de los hospitales como en su reglamentación. Todo ello repercutió en el desarrollo de la enfermería, que desplegó sus bases de acción, plasmándolas en manuales donde se recogían sus conocimientos y actividades.

Estos manuales se orientaban a la formación de los enfermeros. Además liberaron a las prácticas asistenciales de supersticiones propias de la época. Las citadas obras, representan un gran salto para el desarrollo de la Profesión. Su lectura nos da una visión de la enfermería de la época ${ }^{1}$.

Hablar de formación o conocimientos enfermeros en los siglos XVI y XVII puede parecer fantasía histórica. Sin embargo, si la Enfermería quiere emprender un análisis serio de su historia ha de adentrarse en sus raíces, investigando y recuperando los textos primarios en los que se basaron los primeros profesionales ${ }^{2}$.

El Patrimonio Bibliográfico de la Enfermería española constituye una de las señas de identidad más significativas de la profesión. Está formado por obras que hacen referencia a la profesión ${ }^{3}$.

En la segunda mitad del siglo XXI contamos con una herramienta para compartir el conocimiento, como se supone es Internet. Cualquier profesional sanitario puede acceder al conocimiento, y empirismo compartidos, sin necesidad de salir de su sala de estudio. Asegurase de la mejor evidencia científica de un cuidado o técnica de enfermería puede documentarse disponiendo de un Ordenador Personal, tableta o teléfono móvil, conectado a la Red. Lo más usual es consultar la producción científica de los últimos años en bases de datos bibliográficas especializadas. Rara vez se consultan publicaciones de más de 10 años de antigüedad. Menos aún información de siglos anteriores.

Para poder consultar textos de enfermería, considerados Fondo Antiguo, podemos acudir a las bibliotecas digitales. Una vez elegida la biblioteca digital y seleccionada la búsqueda podemos en breve espacio de tiempo, tener ante nuestros ojos un ejemplar original. Podemos, incluso, descargarlo y almacenarlo en nuestros directorios personales y consultar los fundamentos de la formación de enfermeros en los siglos XVI y XVII, comparándolo con nuestros conocimientos actuales. Podría sorprendernos.

Este artículo forma parte de la tesis Referencias al aparato digestivo en los textos de materia médica impresos en España durante el Renacimiento y recuperado en bibliotecas digitales, pendiente de lectura y defensa en la Universidad de Murcia

\section{OBJETIVOS}

Previa identificación en bibliografía consultada, proponemos la recuperación en bibliotecas digitales de los textos de enfermería impresos en España durante los siglos XVI y XVII. 


\section{METODOLOGÍA}

1. Para la fundamentación del estudio e identificación de los textos objeto de estudio se han consultado las bases de datos bibliográficas de Enfermería, Dialnet y Google Académico con las palabras clave: Enfermería, Siglo XVI, Siglo XVII.

2. En la lectura y análisis de la documentación (artículos, tesis y libros) se han identificado los textos de enfermería impresos en España durante el Renacimiento y se han extraído comentarios pertinentes sobre ellos.

3. Se han seleccionado una serie de bibliotecas digitales, principalmente universitarias e institucionales donde se ha procedido a la búsqueda, recuperación y descarga de los textos identificados, obteniendo siempre que ha sido posible una copia en PDF.

\section{RESULTADOS}

Los textos que a continuación se enumeran son los más significativos de los que se han identificado y que contienen referencias directas a Enfermería. También debemos, al menos, citar los de Oliva de Nantes, Melchor Gallego, Ruices Fontecha, entre otros.

\section{Fernández, Andrés. Instrucción de enfermeros para aplicar los remedios a todo género de enfermedades y acudir a muchos accidentes que sobrevienen en ausencia de los médicos. Madrid: Imprenta Real, 1625. (Imagen 1)}

El texto de Andrés Fernández recoge la enfermería practicada en España por su Congregación. Se trata de uno de los textos más antiguos de Europa, escrito por un enfermero y dirigido a la formación de éstos. Su volumen pequeño permitía que los enfermeros pudieran llevarlo encima y consultarlo con facilidad cuando lo necesitasen. En el texto se aprecian esbozos de las actuales funciones de enfermería. En sus páginas, encontramos las funciones asistenciales que el enfermero llevaba a cabo. Comparadas con las que se desarrollan en la actualidad, tienen cierta similitud. Fundamentalmente es la prestación de cuidados al enfermo, la más ampliamente recogida en el tratado, como queda constancia en el propio título. 
Imagen 1: Portada de Instrucción de enfermeros para aplicar los remedios a todo género de enfermedades y acudir a muchos accidentes que sobrevienen en ausencia de los médicos de Fernández, Andrés. Madrid: Imprenta Real, 1625.

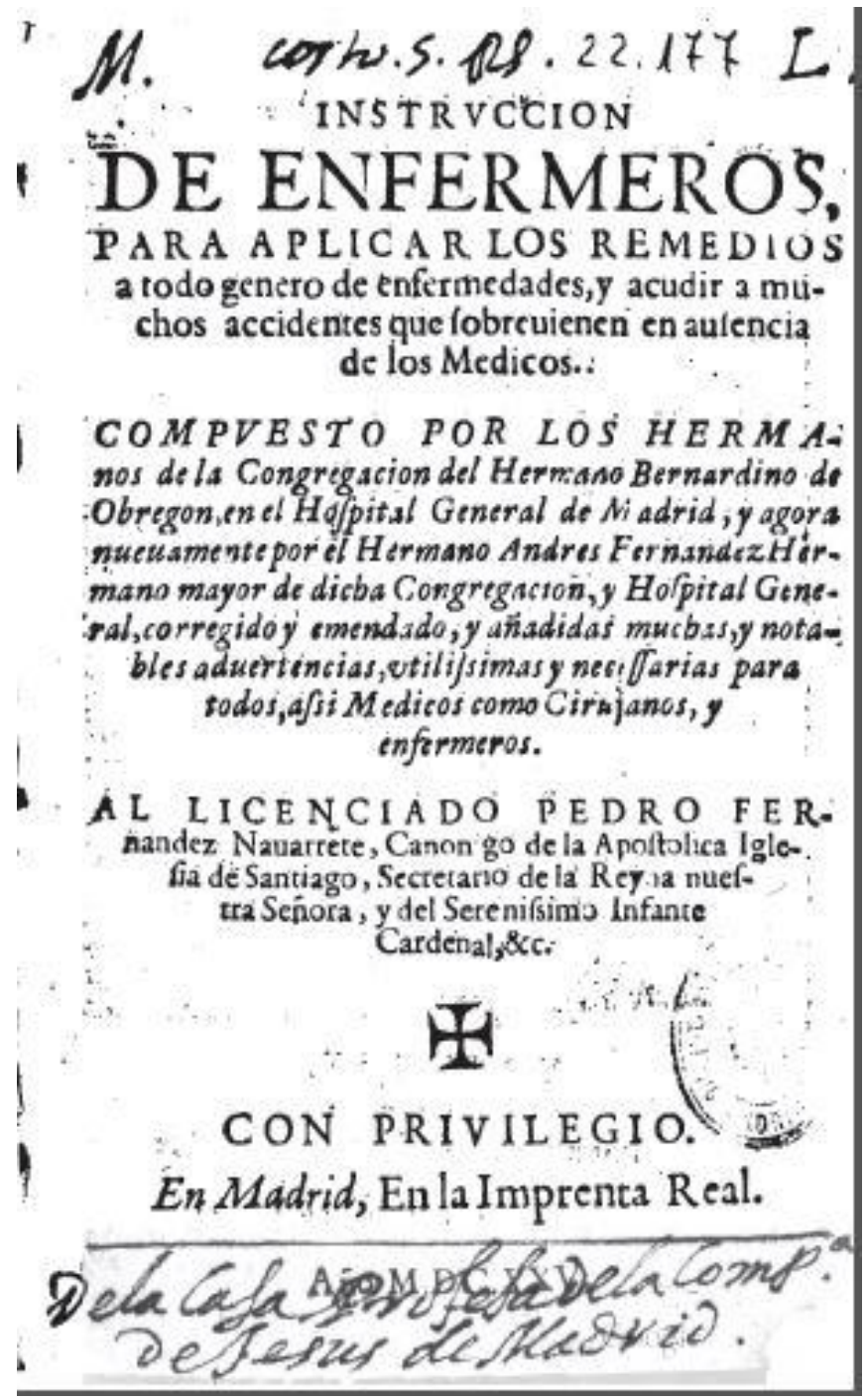

Andrés Fernández, enfermero y fraile, perteneció a la Congregación de Enfermeros Obregones. Trabajó en hospitales de Portugal y Castilla.

Hablar de docencia en la Enfermería del siglo XVII puede parecer temerario; sin embargo, la función docente queda patente cuando el autor escribe: " $Y$ así me pareció cosa muy justa manifestar y enseñar a otros lo que tanto me costó en veinte y cuatro años de experiencia, que con mis desconfianzas aprendí de Médicos muy doctos y experimentados; y persuadido de esta necesidad, y de ver lo que un enfermero padece en un Hospital viéndose con tantos remedios que aplicar a los enfermos afligidos, sin saber cómo lo ha de hazer". ${ }^{4}$

La investigación se centra en la comprobación de la eficacia de preparados medicinales, en la observación continuada de síntomas de distintas patologías y en la ejecución de tareas propias. 
La función de administración queda recogida en las constituciones y reglas de la Congregación; en ellas se tratan los asuntos relativos a la administración interna, elección de empleos y cargos, funciones y tareas de cada uno.

Destacan otras actividades: recepción y registro de enfermos, distribución de los mismos en las diversas salas, separando a los contagiosos, administración de los recursos materiales y humanos, supervisión del trabajo realizado por el personal sanitario del Hospital, etc.

Otro aspecto destacable era la preocupación por dejar constancia por escrito de todas sus actividades, a modo de los actuales registros de Enfermería. El autor recomienda que el enfermero escribiera lo que ordenaren los médicos en relación a las curas y comidas, anotando las horas en las que el paciente tenía más fiebre.

La visión integral de la asistencia a los enfermos que se intuye en la lectura del textos puede tener similitudes con la visión biológica, psicológica y social que propugna en la actualidad la Organización Mundial de la Salud.

El manual de enfermería de Fernández es un libro muy importante en la historiografía de la enfermería. Resalta la relevancia de los cuidados practicados en el siglo XVI en España. La obra es un punto de referencia y un marco de influencia para la cultura de los cuidados y para la ciencia de Enfermería ${ }^{5}$.

Cuando en la actualidad y en buena parte del mundo se reconoce a Florence Nightingale (1820-1910) como la creadora de la Enfermería profesional y moderna, nos encontramos con que en la España de los siglos XVI y XVII existía una Congregación de enfermeros que había puesto en práctica principios que serían formulados dos siglos y medio después por esta ilustre enfermera ${ }^{6}$.

\section{Simón López. Directorio de enfermeros y artífice de obras de caridad. Sin datos: Sin datos, 1650}

El libro de Directorio de Enfermeros de Simón López de 1650, cuyo manuscrito se ha recuperado a finales del siglo XX, continúa la misma línea del texto de Andrés Fernández. El texto de López se realizó con el objetivo de formar e instruir a los que se inician en el oficio de enfermeros y a los que ya ejercían la profesión. El manual supone los primeros intentos de delimitación de los conocimientos propios del enfermero y con ello la definición de la profesión, estableciendo la relación de enfermeros con otros profesionales sanitarios y los marcos de actuación con respecto a los mismos ${ }^{7}$.

\section{Damiá Carbó. Libro del arte de las comadres o madrinas y regimiento de las preñadas y paridas y de los niños. Mallorca: Hemando de Cansoles, 1541}

Es probable que en su época el tratado fuera más una obra difundida entre médicos que un manual para las parteras. Por ello, en ausencia de pruebas documentales, parece probable que las recomendaciones de Carbó, más que una orientación para matronas, fuera el reflejo de su práctica asistencial. Los historiadores de la enfermería consideran, sin embargo, el tratado de Carbó como el más antiguo manual pensado para matronas que se conoce en España. La imagen ideal de la matrona que propone Carbó en el texto se configura a partir de sus expectativas en cuanto a actitudes, capacidades y desempeño profesional. 


\section{Gutiérrez de Arévalo, Pedro. Practica de boticarios, guía de enfermeros, remedios para pobres. Madrid: María de Quiñones, 1634.}

Por último mencionamos el texto de Gutiérrez de Arévalo. En principio el texto es un manual de formación para la preparación de medicamentos y su administración, por parte de los enfermeros. No existe constancia exacta de las intenciones del autor, al incluir a los enfermeros en el título del texto, pero sí de sus intenciones formativas, como sucede con los textos anteriormente citados. El estudio de la obra requiere situarse en el encuadre histórico de la misma.

\section{Recuperacion de los textos en bibliotecas digitales}

En la segunda década del siglo XXI el impacto de las tecnologías de la información y la comunicación, se dirige hacia una progresiva desmaterialización de parte de la realidad, provocando que los objetos materiales sean sustituidos por procesos y servicios cada vez más inmateriales. En este contexto surge la imagen de una biblioteca sin paredes, que permite un acceso remoto a contenidos y servicios bibliotecarios y recursos de información. Es concebida como la alternativa para el logro del acceso universal a los documentos. Las nociones sobre biblioteca virtual, digital e híbrida son tan ambiguas como la mayoría de los conceptos relacionados con las tecnologías de la información. Su definición y funciones varían entre diferentes autores.

Podemos definir biblioteca virtual como aquella donde el usuario tiene acceso a una gran colección de información, de forma inmediata o simultánea mediante el acceso remoto a contenidos y servicios bibliotecarios. Todo ello en soporte de red, lo que brinda acceso a otras bibliotecas en el ámbito mundial ${ }^{8}$.

Las bibliotecas digitales permiten el acceso global a imágenes de documentos de uso restringido (viejos, raros o de uso discutible). Los usuarios tradicionales de este tipo de documentos, investigadores, seguirán siendo escasos, salvo que la biblioteca que los digitalice los difunda y los investigadores utilicen el material ${ }^{9}$.

En nuestro estudio, a excepción de Directorio de Enfermeros de Simón López, los textos han podido ser localizados, recuperados y consultados, destacando, por mayor número de recuperaciones, el texto de Andrés Fernández. (Tabla 1)

Tabla I: Recuperaciones de los Textos por Bibliotecas digitales visitadas'

\begin{tabular}{|l|c|c|c|c|c|}
\hline \multicolumn{1}{|c|}{$\begin{array}{c}\text { BIBLIOTECAS } \\
\text { DIGITALES }\end{array}$} & TEXTO 1 & TEXTO 2 & TEXTO 3 & TEXTO 4 & RECUPERACIONES \\
\hline Europeana & $\mathrm{SI}$ & $\mathrm{NO}$ & $\mathrm{NO}$ & $\mathrm{NO}$ & 1 \\
\hline Digital Castilla y León & $\mathrm{SI}$ & $\mathrm{NO}$ & $\mathrm{NO}$ & $\mathrm{NO}$ & 1 \\
\hline Hathi Trust Digital Library & $\mathrm{SI}$ & $\mathrm{NO}$ & $\mathrm{NO}$ & $\mathrm{NO}$ & 1 \\
\hline Google Books & $\mathrm{SI}$ & $\mathrm{NO}$ & $\mathrm{SI}$ & $\mathrm{NO}$ & 2 \\
\hline Digital Complutense & $\mathrm{SI}$ & $\mathrm{NO}$ & $\mathrm{SI}$ & $\mathrm{NO}$ & 2 \\
\hline Digital Hispánica & $\mathrm{SI}$ & $\mathrm{NO}$ & $\mathrm{NO}$ & $\mathrm{NO}$ & 1 \\
\hline Miguel de Cervantes & $\mathrm{SI}$ & $\mathrm{NO}$ & $\mathrm{SI}$ & $\mathrm{NO}$ & 2 \\
\hline $\begin{array}{l}\text { Universidad Autónoma } \\
\text { de Puebla }\end{array}$ & $\mathrm{SI}$ & $\mathrm{NO}$ & $\mathrm{NO}$ & $\mathrm{NO}$ & 1 \\
\hline
\end{tabular}




\begin{tabular}{|c|c|c|c|c|c|}
$\begin{array}{l}\text { Real Academia Nacional } \\
\text { de Farmacia }\end{array}$ & NO & NO & NO & SI & 1 \\
\hline RECUPERACIONES & $\mathbf{8}$ & $\mathbf{0}$ & $\mathbf{3}$ & $\mathbf{1}$ & $\mathbf{1 2}$ \\
\hline
\end{tabular}

\section{CONCLUSIONES}

El tema propuesto abre las puertas a un campo sin explorar, pero necesario para poder situar a Enfermería en el contexto histórico de cualquier momento y aproximarlo a la Enfermería actual, con el fin de aproximarnos a los conocimientos acerca del cuidado y su aportación a la salud en cada etapa histórica.

Por su estructura y contenido, los tratados Instrucción de enfermeros de Andrés Fernández y el de Simón López, Directorio de enfermeros, son piezas bibliográficas fundamentales que nos ayudan a conocer y entender la Enfermería española de los siglos XVI y XVII, verdaderos orígenes de nuestra enfermería actual.

La publicación de los primeros manuales de formación en Enfermería en las primeras décadas del siglo XVII constituye todo un hito para Enfermería, que goza en el siglo XVII de una excelente práctica y organización y que se plantea cubrir otra de sus funciones: la docente.

Para poder fundamentar este tipo de estudios, en los que se analizan textos de Fondo Antiguo, se hace imprescindible consultar los textos originales. Para ello es preciso acudir a una biblioteca convencional que tenga en su catálogo dicho texto y que éste pueda ser consultado, generalmente con una serie de complejos permisos que tratan de salvaguardar y proteger el patrimonio bibliográfico. Una alternativa cómoda y válida es su consulta con el uso de las bibliotecas digitales. En ellas se puede disponer de ellos de manera rápida y económica; basta con descargar una serie de imágenes o un PDF y obtener el texto completo para su consulta ad hoc.

\section{BIBLIOGRAFÍA}

1. Prieto Moreno J. El arte de curar y de cuidar desde el punto de vista terminológico. Cultura de Cuidados 2001; 5(9):63-70

2. Hernández Martín, Francisca Acerca de la formación de los enfermeros en la obra de Gutiérrez de Arévalo (siglos XVI-XVII). HÍADES 2001; 8: 343-354

3. García Martínez MJ. Ficha número 11: Manual para el uso de Practicantes. Híades. Revista de Historia de la Enfermería 2000; 7: 109-120.

4. Fernández, Andrés. Instrucción de enfermeros para aplicar los remedios a todo género de enfermedades y acudir a muchos accidentes que sobrevienen en ausencia de los médicos. Madrid: Imprenta Real, 1625.

5. Genival Fernandes de Freitas. Antropología y cuidados en el enfoque de San Juan de Dios. Index de Enfermería 2008;17(2):1-7.

6. García Martínez MJ. Cuidar el cuerpo y salvar las almas La Práctica de la Enfermería según el modelo de la Congregación de enfermos obregones. Tesis doctoral dirigida por Salvador Rodríguez Becerra. Sevilla: Universidad de Sevilla, 2007

7. García Martínez, A. C. Análisis del Directorio de Enfermeros de Simón López. Síntesis, Madrid; 1997. 
8. Torres Vargas GA. La biblioteca universal: de Alejandría a la biblioteca virtual. Documentación de las Ciencias de la Información. 1999; 22: 85-93.

9. Peset Mancebo F. Bibliotecas digitales en internet de libro raro, antiguo e incunables. Anales de documentación. 2003; 6: 241-260. 